\title{
ENSINO DA FILOSOFIA: UMA LEITURA CRÍTICA DA FILOSOFIA SUBJACENTE ÀS ORIENTAÇÕES CURRICULARES DO MEC
}

Marcelo Martins Barreira*

\section{RESUMO}

O artigo elabora uma crítica à opção filosófica e pedagógica das Orientações Curriculares para o Ensino Médio elaboradas pelo MEC. Subjaz ao documento uma aprendizagem especializante da filosofia, enfatizando a leitura técnica de textos clássicos da História da Filosofia. Ainda que se deva valorizar a exegese de textos clássicos, tal eixo-conceitual contribuiria para um extenso conteúdo temático que se contraporia a um paradigma democrático de compreensão da especificidade filosófica como "disciplina cultural", caracterizada por "estilos de interrogação" e que seria mais condizente com o ensinar a filosofar no nível médio de ensino.

PALAVRAS-CHAVE: Filosofia. Ensino médio. Orientações curriculares

\begin{abstract}
The article provides a criticism o the philosophical and pedagogical option of the High School Curriculum Orientations developed by the Brazilian Ministry of Education. Embedded in the document is a specialized learning of philosophy, which emphasizes the technique of reading classical texts of the History of Philosophy. While we should value the exegesis of classical texts, that conceptual-axis contributes to an extensive thematic content that is contrary to a democratic paradigm of understanding the philosophical specificity as a "cultural discipline", characterized by "styles of interrogation" and that would be more consistent with the teaching of philosophy in the secondary level of education.
\end{abstract}

KEYWORDS: Philosophy. High school. Curriculum orientations.

* Doutor em Filosofia e Professor Adjunto do Departamento de Filosofia da UFES. E-mail: marcelobarreira@ymail.com 
A valorização da filosofia no ambiente escolar depende de políticas públicas consistentes ancoradas a um movimento social em sua defesa. A filosofia não é uma panaceia para os problemas que assolam a educação. Os que foram seduzidos por ela, sabem, porém, que ela também não é uma moda passageira. A filosofia pode-se usar a metáfora do remédio. Lembremos que, embora polêmica, Derrida (1989) aponta a ambiguidade do termo escritura no Fedro, de Platão. O autor associa, em seu duplo sentido, escritura e phármakon, pois aquela pode ser remédio ou veneno. De fato, o contato com o ensino da filosofia pode envenenar e traumatizar negativamente o educando; outras vezes, ocorre o contrário, o contato com os textos da tradição filosófica se configura numa experiência humanizante e fortificante para a vida do educando. Essa ambiguidade é intrínseca ao ensino de filosofia, posto que a filosofia não possa ser entendida de modo conceitualmente unívoco e definitivo, em consonância com a sua dependência de uma contínua práxis interpretativa.

Nossa tentativa é a de defender — sem a exclusão de outros aspectos, tão ou mais relevantes, de seu ensino - que a filosofia também sirva eficazmente para que o educando enfrente os inúmeros desafios de uma práxis cidadã em contexto democrático. Queremos deixar claro, portanto, que entendemos as Orientações Curriculares para o Ensino Médio como parte desse processo em defesa da qualidade no ensinoaprendizagem do filosofar. Pretendemos neste trabalho, apenas apresentar uma opinião nossa acerca das OCEM e, assim, tentar contribuir com o crescente debate a respeito do "ensinar a filosofar", da qual as orientações do MEC participam.

Constata-se uma nova e crescente demanda por assuntos filosóficos. Demanda repleta de ambiguidades, mas que se tornou um lugar-comum nos corredores da academia e contribuiu para uma maior visibilidade institucional e disciplinar da filosofia; mesmo não tendo sido o fator determinante para a histórica decisão do Conselho Nacional de Educação em favor da obrigatoriedade de sua aprendizagem em todo o território nacional. Surge uma resolução homologada pelo ministro da Educação no dia 11 de agosto de 2006, Dia do Estudante, em que se desdobrou, enfim, na sanção presidencial da Lei $n^{\circ}$. 11.684 no dia 02 de junho de 2008, que altera o Art. 36 da Lei de Diretrizes e Bases da Educação Nacional (Lei nº. 9.394, de 20 de dezembro de 1996). 
Para além de fatores conjunturais, o reconhecimento do valor humano e social que a discursividade filosófica traz para a formação dos estudantes decorre de um longo esclarecimento desta sua relevância. A comunidade filosófica e educadores comprometidos com a qualidade da educação em todo o território nacional capitanearam essa luta desde 1971, data em que a filosofia, em nível nacional, perdeu oficialmente seu status de disciplina obrigatória, consoante a diretriz políticoeducacional do regime militar. Foi no bojo dessa legitimação da filosofia, como disciplina obrigatória na matriz curricular do Ensino Médio, que o Ministério da Educação, em 2006, elaborou as OCEM com um capítulo consagrado à aprendizagem do filosofar. Embora se explique como decorrente da luta acima, o caráter disciplinar da filosofia chega num momento em que se questiona o conceito de "disciplina" como uma espécie de fatia e lote de saber específico no mercado educacional. Numa preocupação de se delimitar fronteiras epistemológicas e, sobretudo, o que é plenamente justificável e determinante para qualquer trabalhador, de se definir a cargahorária docente. Postura que, no entanto, sublinharia uma posse da verdade no tocante a certos assuntos próprios e não uma hermenêutica macroscópica sobre a realidade a partir de múltiplos pontos de vista; logo, privilegiando uma abordagem restritiva e fragmentada da experiência humana. De qualquer modo, compreende-se a posição políticopedagógica das OCEM na luta e defesa de, no mínimo, duas horas aulas semanais, em mais de uma série do Ensino Médio (OCEM, 2006, p. 18), garantindo, assim, o papel formador da filosofia: o de articular noções de modo mais duradouro do que as enciclopédicas informações veiculadas em tempo real. Isso advém da Lei $\mathrm{n}^{\circ}$. 11.684, que torna obrigatória a disciplina Filosofia nas três séries do Ensino Médio; sem que se menospreze, pelo contrário, a capacidade que a filosofia tem de integrar com sucesso projetos transversais. (OCEM, 2006, p. 15)

$$
* * *
$$

As OCEM comentam o Art. 36 da LDB, conforme a redação de 20 de dezembro de 1996. Nesse artigo consta que, ao final do Ensino Médio, o estudante deve "dominar os conteúdos" de Filosofia e Sociologia 
necessários ao exercício da cidadania. A LDB, porém, não apregoaria o monopólio da criticidade de tais disciplinas ou que seriam as únicas que se preocupariam com a condição humana (OCEM, 2006, p. 16). Por isso, a Lei $n^{\circ} .11 .684$ (de 02 de junho de 2008), ao alterar o Art. 36 da Lei $\mathrm{n}^{\mathrm{o}}$. 9.394, de 20 de dezembro de 1996, em sua forma lacônica, não fala mais de conteúdos - em sintonia, portanto, com as duas observações críticas feitas em 2006 pelas orientações curriculares do MEC quanto à pretensa instrumentalização e exclusivismo do saber filosófico (e sociológico) a serviço, ainda que vago e impreciso, da cidadania. De fato, tal instrumentalização transmitiria uma dupla restrição: seja no tocante do papel formativo da filosofia, que se reduziria numa mera funcionalidade social; além de um alijamento epistemológico e axiológico de outras áreas do saber numa contribuição do que seria uma "formação para a cidadania".

O desafio de se pensar o significado do termo cidadania não escapa de uma opção filosófica e, por conseguinte, teórico-valorativa. Esse conceito, como outro qualquer, não é unívoco (OCEM, 2006, p. 24). Apesar disso, não convém a um documento oficial do MEC, direcionado à educadores com opções teórico-valorativas bastante diferenciadas, uma parcialidade epistemológica, o que seria por demais tendenciosa contra a saudável e legítima diferença entre as diversas escolas filosóficas - ainda que, implicitamente, fique difícil não implicar, ao menos implicitamente, certa diretriz conceitual a perpassá-lo. Daí, a conveniência da solução proposta: a de partir da legislação educacional condizente à "educação para a cidadania", tornando-se, aparentemente, uma estratégia de abordagem "neutra" dessa temática. Assim, as OCEM garimparam a legislação para saber, nas entrelinhas, o que esta subentenderia por "cidadania".

O Art. $2^{\circ}$. da Resolução CEB no . 3, de 26 de junho de 1998, que se reporta à LDB, apresenta a dupla esfera valorativa que nortearia e autenticaria uma prática "cidadã" (OCEM, 2006, p. 25): os valores fundamentais ao interesse social, que se traduziria pelo respeito ao bem comum e à ordem democrática; além dos valores que fortaleçam os vínculos de família, os laços de solidariedade humana e de tolerância recíproca. Em linhas bastante gerais e sem enfocar quais seriam os meios de efetivação histórico, a legislação visaria o estímulo e o fortalecimento da socialidade em perspectiva política. $\mathrm{O}$ artigo seguinte $\left(3^{\circ}\right.$.) defende $\mathrm{o}$ 
vínculo entre a vivência escolar e, sem maiores considerações, a alguns princípios que compõem a tradição filosófica — a estética da sensibilidade; a política da igualdade; a ética da identidade —, princípios gerais, em sintonia com a exortação dos valores elencados acima, que serviriam de base para uma práxis educacional coerente com a democracia. Mais do que princípios seriam diretrizes político-pedagógicas a apontarem para um horizonte humano e sóciocultural mais amplo; norteando os educadores da área, desde seus contextos e pontos de vista filosóficos, em vista de um projeto inclusivo de ensinoaprendizagem e de sociedade.

$\mathrm{Na}$ segunda secção das OCEM, ao tratar dos "Objetivos da Filosofia no Ensino Médio", há em seus parágrafos certa ambiguidade no que toca a esses objetivos. No comentário inicial, referente ao Art. 36, inciso II da LDB, prioriza-se uma educação que forneça ferramentas conceituais diante de um conjunto heterogêneo de teorias. Ao estudante resta uma hipotética possibilidade de se posicionar e de correlacionar essas ferramentas conceituais com a sua vida - visto que, segundo as orientações curriculares (OCEM, 2006, p. 28), um conhecimento "útil" não corresponde, tout court, a um saber prático e restrito.

Após tal ênfase, parece haver uma atenuação do que se afirmou, pois tira da Filosofia a sua condição de saber soberano e nega-lhe, ainda, o que seria o extremo oposto dessa sua condição de vértice dos saberes: um conjunto sem sentido de opiniões e sistemas desconexos entre si. Ambas as situações desencorajariam ao educando na tarefa de produzir articuladamente suas próprias ideias. Os conhecimentos de Filosofia devem ser vivos e adquiridos como apoio para a vida, pois, caso contrário, dificilmente teriam sentido para um jovem nessa fase da formação (OCEM, 2006, p. 28); por isso, caberia também ao filósofo/ educador estimular essa ponte entre teoria e vida. No inciso III do Art. 35 da LDB consta que o aprimoramento como pessoa humana indica uma formação não apenas técnica, cuja necessidade é criada frequentemente para seguir a pauta imediata e interessada do mercado e sua lógica produtivista (OCEM, 2006, p. 29).

Subjaz a todo discurso, principalmente ao educacional e filosófico, uma perspectiva, também ela, teórico-filosófica e que fundamenta uma determinada epistemologia. Podemos reconhecer nas orientações oficiais do MEC, de modo sub-reptício, a hegemonia de um eixo-conceitual que, 
apesar de tolerante epistemologicamente no que toca às diversas opções filosóficas, tende para um tipo de discurso de viés técnico e especializante a seu respeito. Uma consideração recorrente das OCEM é a de que a leitura técnica e quase exclusiva dos textos filosóficos, por si só, já trazem os problemas, vocabulários e estilos de se fazer simplesmente filosofia, sem uma necessidade de adjetivação, mesmo a de "política" (OCEM, 2006, p. 27). Nisso está a sua contribuição específica para o "exercício da cidadania"; não em seu possível "lado humanístico" (OCEM, 2006, p. 26). Desse modo, o sentido clássico e forte de "cidadania" fica esvaziado para ressaltar uma sua compreensão difusa na prática filosófica — bem longe, ao que parece, de uma possível filiação a uma crítica à acepção clássica de "política", seguindo os passos de Michel Foucault. Exemplar de uma concepção técnicoespecializante da filosofia feita pelas orientações do MEC é a citação que esta faz de um texto de Milton Nascimento:

Não é possível fazer Filosofia sem recorrer a sua própria história. Dizer que se pode ensinar Filosofia apenas pedindo que os alunos pensem e reflitam sobre os problemas que os afligem ou que mais preocupam o homem moderno sem oferecer-lhes a base teórica para o aprofundamento e a compreensão de tais problemas, e sem recorrer à base histórica da reflexão em tais questões é o mesmo que numa aula de Física pedir que os alunos descubram por si mesmos a fórmula da lei da gravitação sem estudar Física, esquecendo-se de todas as conquistas anteriores naquele campo, esquecendo-se do esforço e do trabalho monumental de Newton. (OCEM, 2006, p. 27)

Esta citação repete a comparação da Filosofia com a Física feita na pág. 17 - quando desvaloriza a realidade cotidiana - e coloca a hipotética base teórica das ciências da natureza, e de sua constituição de "verdades", como modelo e paradigma, para o exercício do filosofar. Essa posição, no entanto, "esquece" que a história da ciência não funciona como uma metodologia de pesquisa científica. Em particular para a Física, a história não serve de "base teórica" para a produção de conhecimento científico. A história da ciência é, sim, pré-ciência. Não foi lendo a história da ciência de sua época que Newton descobriu a lei da gravitação universal. Afinal, 
as bases teóricas da criticidade como afirmarão a seguir, devem ser construídas conceitualmente a partir dos educandos, e não desconsiderando seus pensamentos, valores e sensibilidades.

Diante do que entendemos como sendo uma opção filosófica subjacente às OCEM, indicamos um contraponto a esta opção por meio do mito narrado por Platão em sua obra Protágoras (320c a 328c; traduzida por CASSIN, 2005, p. 331-346). O mito se inspira no maior expoente da sofística (apud WOLFF, 1982) e se estrutura como no L. VII da República - sua antítese paradigmática e teórico-valorativa -, em duas partes: com a narração de uma alegoria (mythos) e, logo em seguida, com a explicação analítica desta por meio de um discurso racional (logos). Protágoras responde à principal aporia socrática ao longo desse texto: se todos são competentes em matéria de excelência política, como admitir que é possível ensiná-la? (320c) A alegoria inicial concebe a origem da pólis com o senso de respeito (aidos) e justiça (diké) dados a cada ser humano por Zeus (322c). Ao inverso do domínio técnico e de sua respectiva desigualdade de competência, há, na cidade democrática, o campo do político com a sua igualdade das virtudes comunitárias. A virtude política, ou seja, o senso de respeito e justiça deve ser o lote de cada um para que haja comunidade. Virtude que é adquirida por todos, junto a todos. Vantajosa a cada um apenas no caso de ser patrimônio de todos.

Por sua relevância cultural e repercussão na consciência comum, a língua, como apresenta Protágoras (328), constitui-se, talvez, na melhor analogia para se falar de virtude política. Não faria sentido afirmar, de um ponto de vista democrático, que se tem mais a língua do que a justiça. "Enquanto se pode ser o único médico em meio a um conjunto de leigos, não haveria sentido algum em ser o único justo em meio a uma comunidade (que além do mais não existiria) de 'selvagens"” (WOLFF, 1982, p. 35). Da mesma forma, não haveria nenhum sentido em ser o único falante de determinada língua. Por isso o uso da língua exemplifica otimamente uma qualidade humana igualmente compartilhada, ainda mais no que tange à necessária repartição (nome, que deu origem a nomos, lei; CASSIN, 2005, p. 332, n.2) equivalente de discursos e vozes (isegoria), equivalência a ser cultivada na pólis democrática. Aprende-se a falar uma língua não tanto ao se decorar um léxico ou ao se conhecer a sua gramática, seu aprendizado 
se dá principalmente numa crescente imersão cultural em que cada um e a sociedade como um todo produzem os múltiplos processos de significação. Nenhum linguista tem o monopólio da cultura em geral - a produção coletiva de significações - e da língua efetivamente falada comumente, apesar das contínuas tentativas formais de sua padronização. A língua é mais do que objeto de uma especialidade científica. Como a virtude política, ela é adquirida por cada um junto a todos. Todos são mestres de todos. Ora, todo mundo deve falar a todo mundo para que a comunidade seja possível; portanto, a língua é um lote de todos e de ninguém.

Conforme a sofocracia platônica apresentada no L. VII da República, o filósofoespecialista explica dialeticamente, com a sua competência epistêmica, o que é a justiça sob a ótica absoluta e vertical do supremo paradigma da cidade ideal: a "ideia do bem" (540a; KOHAN, 2004, p. 113-126). Em oposição a essa postura, o modelo de "verdade" defendido pela sofística propõe uma democrática e igual repartição da virtude política, numa discussão pública (pela doxa) do que seja a justiça. A verdade política não é monopólio dos experts, mesmo daqueles de ética. Ela é tarefa de todos os cidadãos que estabelecemos e reinventamos os efetivos limites e possibilidades de seu exercício no dia-a-dia.

Inspirando-se no modelo ateniense, as verdades jurídicas-políticas na democracia são acordos deliberados a partir de um critério quantitativo - contrapondo ao qualitativo, critério de constituição das verdades técnico-cientificas. No modelo/paradigma de Protágoras, independente de quem participe da discussão pública na ágora, seja um filósofoespecialista ou um "simples" cidadão - nosso coloquial "zé-povinho" ou o idioteuein do Protágoras (327; CASSIN, p. 334, n.31) —, cada opinião tinha legitimamente igual peso. Daí sua concordância com um slogan atual: contra a opinião da autoridade, a autoridade da opinião! $\mathrm{Na}$ democracia somos, em tese, igualmente "competentes" ou igualmente "incompetentes", no tocante ao que deve ser preservado e ao que deve ser inovado nas práticas cotidianas de convivência. $\mathrm{Na}$ antiguidade grega e hoje, no que se refere aos princípios do processo democrático, importaria mais a opinião de cada qual do que a competência técnicocientífica. Daí a relevância do diálogo e da retórica para a vida política que nos une. Por isso, a vida política é mais importante do que a divisão social do 
trabalho e suas diferentes competências técnicocientíficas (o en tekhnei einai de Sócrates, em 319c7-8), que nos divide (VERNANT, 2004, p. 10). Especialistas ou não, compartilhamos de uma coletividade e de sua cultura geral que, em sua dinâmica, possibilitam relações político-sociais. Relações decorrentes de um contexto comunicativo compartilhado pelos interlocutores e cidadãos. Não se deveria subestimar a opção éticopolítica das OCEM em relação ao que seria a melhor aprendizagem filosófica dentre os dois paradigmas apresentados antes, sendo que a mesma suspeita envolve esta nossa posição teórica.

Há uma aprendizagem com Protágoras; digamos que ele faz uma "filosofia da democracia". Temos, então, o retorno da "competência" no final desse relato (328b-c; WOLFF, 1982, p. 38-42). Protágoras se diferencia dos demais por sua competência comunicativa, ensinada a seus educandos. Ensinada a partir da horizontalidade, a verticalidade, digna de honorários (328b), é um reconhecimento posterior e não um "ponto de partida" institucional. Na visão deste, não haveriam nem conceitos e nem temas exclusivamente filosóficos, mas uma maneira filosófica e conceitual de abordá-los, melhor dizendo, a maneira filosófica seria propriamente uma capacidade crítica de elaboração conceitual. Cabe ao educador ter habilidade em reconhecer em sua formação cultural e filosófica diretrizes conceituais e estilos de interrogação (FAVARETTO, p. 45). Ao contrário de uma submissão das opiniões à "verdade" do especialista, com o subsequente silenciamento do educando aos princípios paradigmáticos da especialização filosófica, seria preferível que, conjuntamente, os atores da práxis educacional sejam estimulados a desfundamentarem os dispositivos hermenêuticos que disciplinam determinados procedimentos de rigor metodológico. Eis um caminho de formação, quiçá privilegiado, para que os educandos de Filosofia no Ensino Médio construam os alicerces para sempre novos referenciais autônomos do pensamento em consonância com a situação sócio-cultural de vivência democrática.

Os princípios éticos de uma sociedade democrática dependem da crítica e da criatividade do conjunto dos educandos/cidadãos ao deliberarem sobre o destino da coletividade. Expressões correntes e assumidas acriticamente, tais como cidadania passiva ou resgate da cidadania, possuem certa ambivalência. Caso veja nelas uma distinção entre melhores 
e piores cidadãos teríamos uma contraditio in termini com os princípios democráticos, embora reconheçamos que essas expressões podem, por outro lado, indicar níveis diferenciados de efetividade no exercício dos direitos civis e políticos entre os membros da sociedade. Neste último sentido, o fortalecimento da democracia dependeria da politização das pessoas, que se ocorre, de modo privilegiado, pela participação direta no debate público e nas deliberações públicas; ambos baseados no legítimo entrechoque de ideias que, por sua vez, retroalimenta a democracia. A crise acompanha a democracia, que se reconstrói em sua fragilidade pelo diálogo e pelas ações cidadãs.

A "politização" não se dá pela ineficaz erudição teórica, mesmo se alicerçada em livros sob o rótulo de "filosofia política" - como preconizariam, paradoxalmente, muitos expoentes teóricos dessa temática. Em particular na democracia a politização depende do peso valorativo que se atribui à opinião pública ou ao senso comum. Um enorme peso foi dado à opinião pública pela sofística e um pequeno peso foi dado pelos filósofos clássicos na antiguidade grega. Hoje temos a nova, democrática e legítima sofística dos "intelectuais" (FULLER, 2005) que, habitando dois mundos, o acadêmico e o do senso comum, rompem os estreitos limites de seus muros para publicizarem - nos dois sentidos — a sua opinião em blogs, jornais e revistas, disseminando as convicções a respeito de diversos assuntos, visto que têm direito disso e muitos os leem e ouvem. As linhas gerais desse pensar opinativo contribuem para um caminho sutil e formativo de socialização, visto que tais opiniões se traduzem nos "valores" da coletividade social.

Os seres humanos são semióticos, têm a capacidade de receber e produzir sentidos e significados, numa circulação de conhecimento, linguagem, ações e afetos. Afirma Favaretto: “A abstração própria do trabalho filosófico não pode ser confundida com um trabalho pedagógico abstratizante" (2004, p. 52). O que não se traduz numa mera panorâmica da tradição filosófica, mas uma discussão conceitual de suas vivências e dos processos de significação cultural (FAVARETTO, 2004, p. 50). A crítica é possível por meio de determinadas condições: uma capacidade de intervenção na "realidade", reconhecendo nela uma construção de sentidos e relações de poder, num processo contínuo de questionamento 
dos referenciais hermenêuticos das interpretações e reinterpretações desse "real". Isto exigirá um rigor conceitual elaborado com o educando nas aulas de Filosofia, daí o uso de uma coleção de conceitos, doutrinas, problemas; finalmente, a leitura filosófica de textos — filosóficos ou não —, ou seja, a análise dos pressupostos neles subtendidos na produção de seus processos de significação (FAVARETTO, 2004, p. 51). A crítica sobre tais processos seria a singularidade do saber filosófico (FAVARETTO, 2004, p. 50) e não conteúdos fechados e prontos para consumo.

A Filosofia cobra uma autocrítica, isto é, ela exige uma criticidade da crítica filosófica em seus pressupostos teórico-valorativos. No dizer de Favaretto, a enunciação filosófica é "um trabalho de elaboração do pensamento sobre o seu próprio sentido" (2004, p. 48). Cada filósofo educador visa a uma pretensa externalidade significativa acerca de seus próprios processos culturais e históricos. Por sua vez, na educação da inteligibilidade, o filósofo educador deve fornecer as condições de estimular e desenvolver a criticidade do educando (FAVARETTO, 2004, p. 46). Ao nosso ver, o diálogo e o confronto de opiniões se gestam num compromisso mútuo e que é o pilar de uma "educação para a cidadania", seja do que tipo for. Não esqueçamos a frase de Ricoeur (1996, p. 144): "a 'tensão' também é 'diálogo'. Mas, em 'contrapartida', esse diálogo recairá nos compromissos vergonhosos se ele deixar de ser tensão" - valeria, neste trabalho, em que pese o cunho antidemocrático de sua neutralidade axiológica e pretensão objetivista, um resgate do conselho pedagógico de Platão, no L. VII da República, ao educando de filosofia: "aproximar e provar o sangue, como os cães" (537a), preparando-o para a criticidade e o combate conceitual.

O fundamental seria propor aos educandos situações pedagógicas desafiantes conceitualmente a partir de seus preconceitos, além de outras concepções e vivências da "realidade", permitindo-lhes que se orientem no pensamento, ou seja, permitindo-lhes construírem atitudes de discernimento que produzam configurações do pensamento - o que não excluiria a tradição filosófica, evidentemente. (FAVARETTO, 2004, p. 49). Capacitar o educando a fazer uma leitura múltipla do "real" pressupõe uma Filosofia vinculada aos processos culturais de significação, em especial, a uma tomada de posição diante de quaisquer produções textuais, 
particularmente as filosóficas. Procedimento que permitiria ao educando conjugar um repertório de conhecimentos e de procedimentos básicos de pesquisa filosófica. Tais pressupostos e tomadas de posição - comum à pesquisa filosófica relevante e de qualidade, de que matiz for - se configurariam num caminho indispensável para a formação (Bildung) e o "exercício da cidadania". Assim, não se identificando com um simples e linear uso explícito da semântica política, que poderia, como outros conceitos, ser trabalhada como uma mera aquisição de conteúdos, de erudição e de treinamento (Ausbildung) técnicoespecializante em história da Filosofia, num paradigma estéril e acrítico.

$* * *$

A terceira parte, intitulada "Competências e habilidades em Filosofia", opõe-se à memorização bruta ou fatual de conteúdos enciclopédicos, a serem memorizados pelos educandos de Filosofia. Por isso, o que se espera do educador competente em Filosofia (OCEM, 2006, p. 31), de acordo com as diretrizes curriculares aos cursos de graduação em Filosofia e pela Portaria INEP n ${ }^{\circ}$. 171, de 24/08/05, que instituiu o Exame Nacional de Desempenho dos Estudantes (Enade) de Filosofia, seria: a) apresentar um modo especificamente filosófico de se formular e propor soluções a problemas; b) ter uma consciência crítica sobre conhecimento, razão e realidade sócio-histórica; c) ser capaz de análise/interpretação/ comentário de textos teóricos; d) levantar as importantes questões acerca do sentido e de significado da própria existência e da produção cultural; e) interpretar a filosofia e a produção científica, artística, tendo em vista o agir pessoal e político; f) relacionar o exercício da crítica filosófica com a promoção integral da cidadania - com o respeito à pessoa, dentro da tradição de defesa dos Direitos Humanos.

Há, neste ponto, porém, certa duplicidade conceitual — por consequência, não articulada ou matizada —, quiçá para acomodar a diversificada maneira de a comunidade filosófica nacional entender o que significa a Filosofia e o seu aprender. Haveria uma ênfase técnicoespecializante, distinta da que é recomendada no parágrafo anterior 
— em consonância com as posições apresentada antes, de Celso Favaretto. As OCEM subentendem, priorizam e justificam o que seria uma "harmonia" entre os níveis médio e superior de ensino, que se complementariam e se solicitariam; no entanto, numa comparativa relação de verticalidade. A noção de competência se entrelaça com a posição filosófica que perpassa o item "identidade da Filosofia" (2006, p. 22), que só pode ser lida e reconhecida à luz das matrizes conceituais do saber filosófico (OCEM, 2006, p. 30). Para as orientações do MEC, tanto na graduação quanto na pós-graduação, o ponto de partida para a leitura da realidade é a sólida formação em história da Filosofia. Embora se reconheça nessa opção historiográfica a sua diferença para com uma mera história de ideias, sem conexão entre as mesmas, ou num "movimento retilíneo uniforme" em que os últimos autores e sistemas de pensamento seriam necessariamente mais "verdadeiros".

Conforme as OCEM, os textos clássicos não seriam o ponto de chegada do aprender a filosofar, mas o ponto de partida, numa inversão do que seria o ponto de partida e o ponto de chegada! O ponto de partida é a vida efetiva do educando e o "mundo" circundante; o ponto de chegada é que seriam os textos clássicos. Clássicos não tanto por serem marcos da história da Filosofia como algo já instituído, mas numa filosofia da história da filosofia, porque trazem questões e sugestões de respostas relevantes e influentes para a nossa época, ainda que controversas. Atenua-se essa inversão com a estratégica citação de Sílvio Gallo: "Filosofia é processo e produto ao mesmo tempo; só se pode filosofar pela história da Filosofia, e só se faz história filosófica da filosofia, que não mera reprodução" (OCEM, 2006, p. 32). Segundo as OCEM, o desafio é manter a especificidade da disciplina, o recurso ao texto, sem objetivá-lo (OCEM, 2006, p. 33). No entanto, pergunta-se: como não objetivá-lo? Não há quaisquer sinalizações de como se posicionar criticamente sobre o texto; ao contrário, subjaz ao documento uma sobrevalorização da técnica exegética dos textos clássicos como o único caminho autêntico de se resguardar a qualidade da pesquisa filosófica, mimetizando a metodologia estruturalista francesa de Guéroult e Goldschmidt, e sua objetivação meramente filológica do texto em sua arquitetura conceitual. Há de se reconhecer o mérito desse procedimento num momento histórico de pesquisa filosófica no Brasil, em que reinavam 
meros ensaísmos sem maiores rigores conceituais. No entanto, tal procedimento, não propõe, necessariamente, um posicionamento crítico - deixado em segundo plano, quase como uma possibilidade remota. Percebe-se, nas entrelinhas das orientações do MEC, a predominância de uma metodologia de pesquisa filosófica que se configurou hegemônica e paradigmática nas graduações e pós-graduações nacionais - cujos princípios teórico-valorativos foram criticados primeiramente por Paulo Arantes (1994, p. 129; GUIDO, 2004, p. 123) ${ }^{1}$ — e que é colocada implicitamente, ao que nos parece, como modelo para a aprendizagem do filosofar no Ensino Médio.

Não cabe uma depreciação das particularidades da educação em nível médio, a filosofia nesse nível não deveria ser um curso de graduação mitigado, com uma abordagem da história da Filosofia que se torne asfixiante, impedindo certa flexibilidade de conteúdos e desestimulando uma interlocução vivaz entre educador e educando. Apenas a partir dessa interlocução é que se coloca uma panorâmica da tecitura interpretativa de determinados universos de investigação ao longo do legado filosófico ocidental, pressupondo, evidentemente, a leitura de expoentes da história da Filosofia. As OCEM sublinham e partem de certa verticalidade no processo de ensinoaprendizagem e apregoaria a centralidade do viés historiográfico como fonte para o tratamento adequado de questões filosóficas (OCEM, 2006, p. 17) em contato com o texto filosófico clássico.

A ênfase das OCEM é o estudo do texto clássico. Isto significa que os textos clássicos forneceriam a necessária "objetividade" para o discurso filosófico, tal opção didático-pedagógica não demandaria maior complexidade epistêmica para delimitar a sua especificidade no rol dos saberes. Assim, as competências comunicativas se reduziriam à leitura, análise, interpretação e produção de textos. Competências que forneceriam, em grandes linhas, aos educandos - como consequência e, esperase, "ponto de chegada" - as duas dimensões do pensamento filosófico (OCEM, 2006, p. 23): 1) reconstrução racional: elaborações filosóficas

\footnotetext{
${ }^{1}$ Usamos em nosso artigo o texto de Francis Wolff, que foi uma aula inaugural no Departamento de Filosofia da USP em 1982; logo, a referência a Paulo Arantes não significa uma concordância total as teses desse livro.
} 
que se esforçam para explicar teoreticamente um saber pré-teórico que adquirimos à medida que nos exercitamos num dado sistema de regras; 2) crítica: todas as elaborações teóricas motivadas pelo desejo de alterar os elementos determinantes de uma "falsa" consciência e de extrair disso consequências práticas (OCEM, 2006, p. 24). Logo, poderíamos esperar que um graduado em filosofia possa desenvolver no estudante do Ensino Médio competências e habilidades marcadas por uma sólida formação em história da Filosofia (OCEM, 2006, p. 32), considerada, aí, como sendo o que caracteriza a "formação" filosófica, o que se vê nos elementos preconizados pelas orientações do MEC: a) compreender os principais temas, problemas e sistemas filosóficos; b) servir-se do legado da tradição filosófica para dialogar com as ciências e as artes e para problematizar as interpretações da "realidade"; c) transmitir o legado da tradição e, num momento segundo e remoto, o gosto pelo pensamento inovador, crítico e independente.

Nesse prisma estão as competências e habilidades a serem desenvolvidas em Filosofia e que se dividem em três grupos: Representação e comunicação; Investigação e compreensão; contextualização sociocultural (OCEM, 2006, p. 34). Traduzindo essas competências e habilidades para as aulas de Filosofia, com o fito de fornecer elementos para o educador escolher e elaborar o conteúdo programático, ao longo da quarta parte - a respeito dos conteúdos de Filosofia - são elencados os pontos relevantes para a garantia de que os educandos obtenham as condições mínimas de especialização especificamente filosófica (OCEM, 2006, p. 35). Os 30 itens assinalados — exatamente os mesmos itens a serem exigidos dos concluintes da graduação de Filosofia ao fazerem o Enade em 2008 - corroboram com a nossa posição de que as OCEM privilegiam a graduação - a falta de referências nas páginas 34 e 35 indicariam a anterioridade dessa lista temática em relação ao Enade de 2008. Logo, o MEC, ao assumi-la na elaboração de seu exame, revela indiretamente a sua (maior) propriedade para o nível superior de ensino, configurando-se um "tiro no pé" do educador de Ensino Médio, que teria outras prioridades pedagógicas e não lhe caberia ter como horizonte de suas aulas uma especialização filosófica precoce de seus educandos. Essa lista quilométrica evoca uma compreensão conteudística da cultura filosófica 
em sua impostação historiográfica. Embora os itens estejam sob a forma de temas, o recorte destes induz a uma compreensão de que a qualidade de uma formação filosófica seria a leitura competente e direta dos expoentes da história da Filosofia.

No que se refere às habilidades e competências (OCEM, 2006, p. 20), a aprendizagem do filosofar, em consonância com o que se cobra no Enade, implicaria em se ter o mesmo grau de exigência e igual conteúdo nos cursos de bacharelado e de licenciatura; apesar dessas palavras, com este curso, de acordo com o paradigma hegemônico, numa posição aparentemente subalterna ao de bacharelado. Em ambos os cursos, em que pese os itens acima, o eixo central de um currículo de graduação deveria ser composto pelas cinco subáreas da Filosofia - e que, em geral, com a mesma nomenclatura, são matérias da graduação: história da Filosofia; Teoria do Conhecimento; Ética; Lógica e Filosofia Geral: problemas metafísicos.

Reconhecendo-se o peso epistemológico da subdivisão canônica da Filosofia nessas subáreas, ousaríamos, então, propor uma nova "harmonia" entre os níveis médio e superior de ensino. Proporíamos uma abordagem adversa acerca do que seja a competência filosófica, em contraponto a uma cultura filosófica de viés historiográfico, priorizando, ao contrário, a capacidade de crítica e de reelaboração conceitual do educando a partir de diversas correntes filosóficas. Processo a ser construído e operacionalizado a partir dos universos investigativos de questionamento e debate que perpassam as subáreas da Filosofia - com o cuidado, contudo, de se evitar uma terminologia técnica e difícil, possivelmente pouco atrativa aos estudantes. Seria a possibilidade de se dividir o conteúdo programático a partir de universos investigativos. Em que pese um enxugamento temático ou uma simples reorganização temática, tais temas são propriamente questões filosóficas. Como se colocou antes, a respeito do paradigma democrático, não haveriam temas exclusivamente filosóficos, mas estilos de interrogação. A expressão "eixotemático" demonstra a ideia de uma fixidez conceitual da Filosofia em cânones fixos e fechados, não contribuindo para a construção de novos referenciais, a exemplo do que elaboramos exatamente com a expressão "eixotemático". Talvez coubesse uma nova semântica conceitual condizente a esta nova proposta pedagógica: a de mediar ao educando a sua capacidade de crítica e reelaboração conceitual, 
numa maior fluidez temática para o exercício do filosofar, habilitando-o a uma produção textual numa reelaboração rigorosa de conceitos.

Para não se estabelecer uma univocidade conceitual ou qualquer outro tipo de doutrinação teóricovalorativa que desrespeite a pluralidade de pontos de vista filosóficos e uma abertura epistemológica, é preferível um estímulo a universos investigativos que deveriam ser continuamente checados quanto à sua consistência conceitual e operacionalidade didático-metodológica para o processo de aprendizagem do filosofar. O que permitiria, paradoxalmente, um maior estímulo ao diálogo interdisciplinar, sobretudo com as outras disciplinas da área de humanas, atenuando, assim, sua "disciplinaridade". Um currículo de Filosofia deve contemplar a diversidade sem desconsiderar o educador em suas próprias posições teórico-valorativas, sem impedir que as defendam. Existem filosofias, isto é, diversas correntes de pensamento, o que jamais se deveria menosprezar na orientação do pensar (OCEM, 2006 , p. 21). A liberdade de opção teórico-valorativa não restringe seu papel formador, muito pelo contrário, as doutrinações é que podem sufocar a própria possibilidade do filosofar e de se estabelecer um diálogo com as outras disciplinas (OCEM, 2006, p. 19).

Uma abordagem investigativa do pensamento filosófico é uma questão filosófica sobre o aprender a filosofar. Deveríamos discutir acerca da "não-neutralidade" na escolha dos chamados "temas filosóficos", cuja adjetivação já seria de per si um posicionamento filosófico. A Filosofia é uma disciplina de forte viés valorativo. Um exemplo desse traço "ideológico" encontra-se no tema "senso comum/ideologia". Em que pese uma possível análise contra-hegemônica - como seria um estudo mais etimológico alheio à etiqueta marxiana, não seria conveniente subestimar esta sua herança filosófica, então tornada clássica e, também ela, ideológica. Marca que, por isso mesmo, poderia funcionar como uma "camisa de força" epistemológica para os educadores, que prefeririam eleger outras perspectivas de análise sobre o universo social e político-cultural.

$\mathrm{Na}$ quinta e última parte, "Metodologia" (OCEMs, 2006, p.36), de novo, enfatiza-se a história da Filosofia. Ainda que se discorde da metodologia mais empregada na aprendizagem do filosofar - o uso de livros didáticos e da aula expositiva (OCEM, 2006, p. 37). As OCEM afirmam que se deve manter a centralidade do texto filosófico, de 
preferência em suas fontes primárias. Por consequência, diríamos que, segundo a opção teórico-valorativa hegemônica no conjunto do texto do MEC, a particularidade do nível médio de ensino seria a sua imaturidade acadêmica, um primeiro caminho para a posterior especialização filosófica. Haveria, portanto, a partir do nível médio, uma linha acumulativa de conteúdos filosóficos que serviriam como pré-requisitos para um nível superior, em seu duplo sentido, de capacidade técnico-filosófica.

$$
* * *
$$

Cabe, à guia de conclusão, ressaltar que as OCEM estimulam maiores discussões, como a que pretendíamos fazer neste artigo, visto apresentar-se como orientações. Essas novas orientações curriculares do MEC não são leis, mas servem de base para uma discussão sobre os processos de consolidação institucional do ensinoaprendizagem específico de Filosofia.

Em nossa leitura crítica não queremos deixar de reconhecer os elementos positivos das orientações do MEC. De início, deve-se sublinhar o fato de elas serem, tão só, orientações gerais. Há de se aquiescer com o diagnóstico ali presente acerca da situação didático-pedagógica da Filosofia em sua efetiva implantação nas redes estaduais de ensino público em todo o território nacional, onde encontramos dois extremos preocupantes: a presença de educadores improvisados ou não-qualificados na docência de Filosofia, a serem desencorajados ou estimulados a se capacitarem para tanto. Ademais, decorrente dessa deficiência na formação filosófica, concordamos com a posição das OCEM quando aponta o perigo e a precariedade do "ecletismo" desses professores, que são inertes ou incapazes de se adentrarem na complexidade das questões da tradição filosófica (OCEM, 2006, p. 38). É preciso estar à altura da elevada qualidade que deve caracterizar o trabalho de educadores que ensinam o filosofar (OCEM, 2006, p. 39). Não tenhamos ingenuidade, não se improvisa na aprendizagem do filosofar; no entanto, se deve ter a cautela de não se engessar o educador de Filosofia do Ensino Médio com a sobrecarga de um horizonte conteudista de ensino. 
A especificidade da contribuição da Filosofia é sua capacidade de se situar "na cultura como modo de produção de sistemas de significação" (FAVARETTO, 2004, p. 44); prerrogativa cultural que, paradoxalmente, capacita-lhe a elaborar questões originárias acerca da cultura e da sociedade na qual se insere. A Filosofia se caracteriza por ser uma "disciplina cultural", conforme a expressão de Favaretto (2004, p. 50). Platão e Hegel são referenciais desse paradoxo da relação entre Filosofia e cultura em sua tradição metafísica (VAZ, 1993). Desde sua origem, a Filosofia participa de um processo cultural e, ao mesmo tempo, tenta fundamentá-lo como se dele fosse alheia. Condição originária, talvez, do filosofar, confundindose com sua própria identidade - ao ponto de, a elaboração metafórica produzida pelo ethos grego, tornar-se motivo e ocasião de releituras dessa herança e de questionamentos num contexto pós-metafísico e multicultural. Ora, numa perspectiva plural e complexa do "real", nada se pode saber desde um modo e princípios absolutos. Logo, tudo pode ser discutido.

A retomada da democracia com o reconhecimento valorativo de suas "verdades" plurais pelos pensamentos pós-metafísicos de matiz hermenêutica, erige o diálogo como um imperfeito e peregrino paradigma para a formação cidadã, sempre inconclusa. O paradigma democrático, apresentado e defendido neste artigo, permite a indispensável autonomia do educando para uma (re) construção crítica dos processos sócio-culturais de significação e para uma efetiva atuação ética e solidária. Diante de um contexto de saberes rizomáticos e não-hierarquizados entre si, caberia ao circuito educacional orientar-se numa horizontalidade e efetividade social em seus processos de ensinoaprendizagem. Procedimento ético-político que, no caso de uma sua extensão ao âmbito educacional - não só à sala de aula, mas também à administração e ao currículo, bem como à cargahorária docente - valoriza as vivências do educando e sua autonomia investigativa, ampliando a esfera escolar para as que hoje dificilmente atingidas. O que será possível apenas numa impostação filosófica de cunho democrático, oposta da racionalidade e do paradigma ainda hegemônicos. 


\section{Referências}

ARANTES, P. E. Um Departamento Francês de Ultramar: estudos sobre a formação da cultura filosófica uspiana. Rio de Janeiro: Paz e Terra, 1994. CASSIN, B. O Efeito Sofístico. São Paulo: Editora 34, 2005.

DERRIDA, J. La Pharmacie de Platon. Paris: Flammarion, 1989.

FAVARETTO, C. F. Filosofia, ensino e cultura. In: KOHAN, W. (Org.). Filosofia: caminhos para seu ensino. Rio de Janeiro: DP\&A Editora, 2004.

FULLER, S. The Intellectual: The Positive Power of Negative Thinking. London: Icon, 2005.

GUIDO, U. A filosofia no vestibular. In: KOHAN, W. (Org.). Filosofia: caminhos para seu ensino. Rio de Janeiro: DP\&A Editora, 2004.

KOHAN, W. O. Sócrates, a educação e a Filosofia: de herói a anti-herói. In: GALLO, Sílvio; DANELON, Márcio; CORNELLI, Gabriele. (Org.). Ensino de filosofia. Teoria e Prática. 1 ed. Editora da Unijuí, 2004. v. 1, p. 113-126. Orientações Curriculares do Ensino Médio. Brasília: MEC/SEB, 2004. BRASIL.

PERELMAN, C. \& OLBRECHTS-TYTECA, L. Tratado da Argumentação - A Nova Retórica. São Paulo: Martins Fontes, 1999.

PLATÃO. A República. Lisboa: Calouste Gulbenkian, 1990.

RICOEUR, P. Leituras 3: As Fronteiras da Filosofia. São Paulo: Loyola, 1996.

VAZ, H. C. de L. Filosofia e Cultura na tradição ocidental. Síntese Nova Fase. v. 20, n. 63 (1993) 533-578.

VERNANT, J. -P. A Grécia e nós. Folha de São Paulo, 08 ago. 2004. Caderno Mais! p. 10.

WOLFF, F. Filosofia grega e democracia Studio, São Paulo. n. 14, p. 7-48, 1982.

Data de registro: $26 / 11 / 08$

Data de aceite: 07/12/09 